\title{
A COMPARISON OF INTRAVENOUS ONDANSETRON AND PALONOSETRON IN PREVENTING POST-OPERATIVE NAUSEA AND VOMITING AFTER LAPAROSCOPIC CHOLECYSTECTOMY - A RANDOMIZED DOUBLE-BLIND STUDY
}

\author{
AJAY KUMAR*, SUMITA ADHANA, PUNEET DWIVEDI
}

Department of Anaesthesiology and Critical Care, Deen Dayal Upadhyay Hospital, New Delhi, India. Email: ajayannu@gmail.com Received: 07 June 2018, Revised and Accepted: 19 July 2018

\section{ABSTRACT}

Objectives: Post-operative nausea and vomiting (PONV) is a frequently experienced complication following laparoscopic cholecystectomy. This study was planned to compare the antiemetic efficacy of palonosetron with ondansetron in patients undergoing laparoscopic cholecystectomy.

Methods: A total of 100 patients undergoing laparoscopic cholecystectomy were randomized into two groups. Group 0 (n=50) received ondansetron $(8 \mathrm{mg})$ and Group P $(\mathrm{n}=50)$ received palonosetron $(0.075 \mathrm{mg}) 3 \mathrm{~min}$ before induction of anesthesia. Post-operatively, patients were assessed for the occurrence of nausea, retching, or vomiting at $0-2,2-6,6-24,0-24$, and $24-48 \mathrm{~h}$ time intervals. The overall incidence of PONV in time frame (0-48 $\mathrm{h}$ ) was determined. The need of rescue antiemetic, side effect profile, and patient satisfaction scores were also assessed.

Results: The incidence and severity of nausea at all the time intervals were comparable in the two groups. The incidence of vomiting was significantly less in Group P as compared to Group 0 in $0-2 \mathrm{~h}(2 \%$ vs. $14 \%, \mathrm{p}=0.027)$ and $0-24 \mathrm{~h}$ time intervals $(10 \% \mathrm{vs} .30 \%$, $\mathrm{p}=0.012)$. The overall incidence of PONV in $0-48 \mathrm{~h}$ was lesser in Group P as compared to Group 0 ( $28 \%$ vs. $50 \%$, $\mathrm{p}=0.024)$. Rescue antiemetic was required in greater number of patients in Group 0 as compared to Group P (p=0.038). Side effect profile and patient satisfaction scores were comparable in the two groups.

Conclusion: Palonosetron is better than ondansetron in lowering the overall incidence of PONV in $0-48 \mathrm{~h}$ time interval, in patients undergoing laparoscopic cholecystectomy.

Keywords: Palonosetron, Ondansetron, Post-operative nausea and vomiting, Laparoscopy, Cholecystectomy.

(c) 2018 The Authors. Published by Innovare Academic Sciences Pvt Ltd. This is an open access article under the CC BY license (http://creativecommons. org/licenses/by/4. 0/) DOI: http://dx.doi.org/10.22159/ajpcr.2018.v11i12.27712

\section{INTRODUCTION}

Pain, nausea, and vomiting are major perioperative concerns of patients [1]. Post-operative nausea and vomiting (PONV) is not only an unpleasant and distressing experience for the patient but also in severe cases may cause problems such as dehydration, electrolyte imbalance, suture dehiscence, bleeding, and esophageal rupture [2,3]. The incidence of PONV ranges between 10 and $78 \%$ depending on patientspecific, anesthesia, and surgery-related factors [4].

PONV has a complex multifactorial etiology involving multiple receptor pathways at peripheral, central, or both sites [5]. Role of several neurotransmitters such as serotonin, dopamine, muscarine, acetylcholine, neurokinin-1, histamine, and opioids has been implicated in PONV [5]. Antiemetic drugs that include serotonin 5-HT3 (5-hydroxytryptamine-3) receptor antagonists, dopamine receptor antagonists, histamine $\mathrm{H}_{2}$ receptor antagonists, anticholinergic agents, and corticosteroids have been tried effectively in the prevention of PONV [6]. In comparison to other antiemetics, 5-HT3 receptor antagonists are effective antiemetic drugs associated with fewer side effects such as sedation or extrapyramidal symptoms [7]. Ondansetron, a first-generation $5-\mathrm{HT}_{3}$ receptor antagonist [8], is widely used as an antiemetic, in varied post-operative settings and clinical situations [7]. Palonosetron, a second-generation 5-HT3 receptor antagonist, due to its unique pharmacodynamic characteristics has a higher receptor affinity, greater potency, and longer duration of action as compared to other 5-HT3 antagonists [9].

Studies comparing palonosetron with ondansetron for PONV prophylaxis in patients undergoing laparoscopic cholecystectomy for 48-h duration are sparse, and most comparisons are for $24 \mathrm{~h}$. We undertook the current study to evaluate the efficacy of palonosetron for the prophylaxis of PONV for $48 \mathrm{~h}$ and compare it to that of ondansetron in patients undergoing laparoscopic cholecystectomy. The primary outcome measure was the overall incidence of PONV in 0-48 h, and the secondary outcome measures were incidence and severity of nausea, incidence of vomiting, number of patients requiring rescue antiemetic, side effects, and patient satisfaction rate.

\section{METHODS}

This prospective, randomized, double-blind study was conducted in a tertiary care hospital, New Delhi, India, after obtaining approval from the hospital ethics committee. The study has been registered with the Clinical Trials Registry, India (CTRI/2017/08/009295).

A total of 100 patients, in the age group of 18-60 years, of either sex, weighing 40-80 kg, American Society of Anesthesiologists physical status classification I-II, scheduled to undergo laparoscopic cholecystectomy under general anesthesia with duration of surgery $<2 \mathrm{~h}$ were included in the study. The exclusion criteria included menstruating, pregnant, or lactating women; hypersensitivity to study medication; previous history of PONV or motion sickness; receiving drugs with known emetic or antiemetic effect within $24 \mathrm{~h}$ before surgery; having received cancer chemotherapy within 4 weeks or emetogenic radiotherapy within 8 weeks; smokers, obese, diabetes, psychiatric diseases, or gastrointestinal tract disease; alcohol or substance abuse; and patients requiring continuous gastric suction in post-operative period.

Patients were advised to fast overnight and received alprazolam $(0.25 \mathrm{mg})$ tablet as premedication night before and $2 \mathrm{~h}$ before surgery 
with a sip of water. Patients were randomly allocated into two groups, ondansetron group (Group 0, $\mathrm{n}=50$ ) or palonosetron group (Group P, $n=50$ ) using lottery method. Concealment of allocation was done using sequentially numbered, opaque, sealed envelopes that were numbered in advance, and were sequentially opened after the participant's name, and other details were written on the appropriate envelope. The study medication was administered in a double-blind manner, and neither patient nor observer were aware of the drug administered, either before or during the observation period following surgery. Group 0 patients received $8 \mathrm{mg}(4 \mathrm{ml})$ of ondansetron, while Group P patients received $0.075 \mathrm{mg}(1.5 \mathrm{ml})$ palonosetron diluted up to $4 \mathrm{ml}$ with normal saline, intravenously.

In the operation theater, standard monitors (electrocardiogram, noninvasive blood pressure, and pulse oximeter) were applied and baseline readings noted. Intravenous access was secured using 18-gauge intravenous cannula. 3 min before induction of anesthesia, study drug, depending on the group allocation, was administered intravenously. Following induction of anesthesia with fentanyl $(2 \mu \mathrm{g} / \mathrm{kg})$, thiopentone ( $5 \mathrm{mg} / \mathrm{kg})$, an muscle relaxant vecuronium bromide $(0.1 \mathrm{mg} / \mathrm{kg})$ was given to facilitate tracheal intubation. Anesthesia was maintained with isoflurane in a mixture of oxygen and nitrous oxide. Nasogastric tube was inserted for gastric decompression, as it was a surgical requirement.

During surgery, intra-abdominal pressures following carbon dioxide gas insufflation were maintained between 10 and $12 \mathrm{~mm} \mathrm{Hg}$. The end-tidal carbon dioxide concentration was maintained between 35 and $40 \mathrm{~mm} \mathrm{Hg}$ throughout the surgery. For post-operative analgesia, diclofenac (75 mg) IV was given and surgical port sites were infiltrated with $0.25 \%$ bupivacaine at the completion of surgery. Nasogastric tube was removed following gastric decompression, and residual neuromuscular blockade was reversed with neostigmine and glycopyrrolate. Hemodynamic monitoring was done throughout the surgery. Any episode of hypotension (systolic blood pressure $<90$ $\mathrm{mm} \mathrm{Hg})$ or hypoxia $\left(\mathrm{SpO}_{2}<95 \%\right)$ was noted and treated accordingly. Post-operatively, patients were assessed for the occurrence of nausea, retching, or vomiting at $0-2,2-6,6-24,0-24$, and 24-48 $\mathrm{h}$ time intervals. Patients' complaining of severe nausea, retching, or vomiting was given $10 \mathrm{mg}$ IV metoclopramide, a dopamine antagonist [10] as rescue antiemetic. Side effects, if any, such as dizziness, headache, and constipation were also evaluated.

Nausea was defined as an unpleasant sensation with awareness of the urge to vomit. Retching was defined as labored, spasmodic, rhythmic contractions of the respiratory and abdominal muscles, without the expulsion of gastric contents, and vomiting was defined as forceful expulsion of stomach contents from the mouth [11]. For the purpose of this study, retching was considered as vomiting episode. Nausea was graded on a four-point scale (0: No nausea; 1 : Mild nausea; 2 : Moderate nausea; and 3: Severe nausea) [7]. The overall incidence of PONV (cumulative incidence of nausea, retching, and vomiting) at $0-48 \mathrm{~h}$ was determined at the end of the study. Patients were also asked to rate their satisfaction of PONV control, at the end of $48 \mathrm{~h}$, using a 5-point scale ( 1 = very satisfied; 2 = somewhat satisfied; 3 = neither satisfied nor dissatisfied; 4 = somewhat dissatisfied; and 5 = very dissatisfied).

\section{Statistics}

Previous studies [7,12] found the incidence of PONV to be $66 \%$ in ondansetron group and $42 \%$ in palonosetron group. Based on these figures, sample size was calculated by a power analysis using onetailed, alpha value $(0.05)$ and power $80 \%$, and it was estimated that a minimum of 48 patients per group would be required to show $25 \%$ difference in the incidence of PONV between the groups. In total, 100 patients were enrolled and they were randomly assigned into two study groups of 50 each.

Statistical analysis was performed using SPSS for Windows, version 16.0 (SPSS Inc., Chicago, IL, USA). Continuous variables - age, weight, and duration of surgery - are presented as mean \pm standard deviation.
Categorical variables - ASA class, sex distribution, nausea incidence and grade (severity), vomiting incidence, overall PONV, number of patients requiring rescue antiemetic, side effects, and patient satisfaction rate - are presented as absolute numbers or percentages.

The comparisons of normally distributed continuous variables between the groups were performed using independent Student's t-test. Nominal categorical data between the groups were compared using Chi-square test or Fisher's exact test as appropriate. Patient satisfaction ratings were compared on the basis of Student independent t-test. For all statistical tests, "p $<0.05$ was taken to indicate a significant difference."

\section{RESULTS}

A total of 120 patients were assessed for eligibility. Of these, 20 patients were excluded, as 15 patients did not meet inclusion criteria and 5 patients declined to participate. Remaining 100 patients were randomized into the two study groups.

There were no differences in age, weight, sex, ASA class, and mean duration of surgery between the two groups (Table 1).

The incidence and severity of nausea were comparable in the two groups at all the time intervals as shown in Table 2. The incidence of vomiting was significantly less in Group $\mathrm{P}$ as compared to Group 0 in $0-2 \mathrm{~h}(\mathrm{p}=0.027)$ and $0-24 \mathrm{~h}(\mathrm{p}=0.012)$ (Table 2). However, it was comparable at all other time intervals, in the 48-h post-operative period, in the two groups. The overall incidence of PONV (cumulative incidence of nausea, retching, and vomiting) in $0-48 \mathrm{~h}$ was significantly lower in palonosetron group (28\%) as compared to ondansetron group $(50 \%, p=0.024)$. Rescue antiemetic was required in greater number of patients in Group 0 (17/50 patients) as compared to Group P $(8 / 50$ patients, $p=0.038)$ (Table 2$)$.

No patient in any group had any episode of oxygen desaturation or hypotension. The incidence of side effects such as headache, dizziness, and constipation in ondansetron and palonosetron groups $(4 \%, 4 \%$, and $0 \%$ and $0 \%, 4 \%$, and $4 \%$, respectively) was comparable. Patient satisfaction ratings were also comparable in the two groups $(\mathrm{p}=0.070)$, (Table 2).

\section{DISCUSSION}

Laparoscopic surgery involves the creation of a pneumoperitoneum; this increases the risk of PONV due to the stimulation of mechanoreceptors and increased serotonin (5 HT) synthesis [13]. The incidence of PONV following laparoscopic surgery is reported to be as high as $70-85 \%[14,15]$. Apart from the complications $[2,3]$ associated with PONV, patients find it extremely distressing, making it important to prevent its occurrence for patient comfort and well-being. Among the antiemetic drugs given for PONV prophylaxis, 5-HT3 receptor antagonists are widely used drugs due to a favorable side effect profile [7]. The antiemetic efficacy of ondansetron is well established for both PONV prophylaxis and treatment [16]. Palonosetron due to its longer half-life ( $40 \mathrm{~h}$ ) as compared to ondansetron (3.5-5.5 h) may provide for PONV prophylaxis for a longer duration of time that may extend to $48 \mathrm{~h}[16]$.

Table 1: Demographic profile and duration of surgery in the two study groups

\begin{tabular}{llll}
\hline Parameter & $\begin{array}{l}\text { Group } \\
\mathbf{O}(\mathbf{n = 5 0 )}\end{array}$ & $\begin{array}{l}\text { Group } \\
\mathbf{P}(\mathbf{n}=\mathbf{5 0})\end{array}$ & p value \\
\hline Age (year) & $35.98(10.11)$ & $35.16(9.97)$ & 0.699 \\
Weight (kg) & $59.78(7.88)$ & $58.14(8.90)$ & 0.332 \\
Sex (M/F) & $10 / 40$ & $7 / 43$ & 0.424 \\
ASA class (I/II) & $44 / 6$ & $42 / 8$ & 0.564 \\
Surgery duration (min) & $57.88(15.56)$ & $57.66(17.07)$ & 0.473 \\
\hline
\end{tabular}

Data are expressed as mean $( \pm \mathrm{SD})$ or numbers. $\mathrm{P}<0.05$ is statistically significant. SD: Standard deviation 
Table 2: Nausea and vomiting characteristics, patients needing rescue antiemetic, and patient satisfaction rating in the two study groups

\begin{tabular}{llll}
\hline Parameter & $\begin{array}{l}\text { Group } \\
\mathbf{0}(\mathbf{n = 5 0})\end{array}$ & $\begin{array}{l}\text { Group } \\
\mathbf{P}(\mathbf{n = 5 0})\end{array}$ & p value \\
\hline \multicolumn{2}{l}{ Nausea incidence $[$ severity Grade $0 / 1 / 2 / 3]$} & $(\mathrm{h})$ \\
$0-2$ & $3[47 / 0 / 2 / 1]$ & $4[46 / 0 / 1 / 3]$ & 0.277 \\
$2-6$ & $2[48 / 2 / 0 / 0]$ & $3[47 / 2 / 1 / 0]$ & 0.237 \\
$6-24$ & $4[46 / 2 / 1 / 1]$ & $1[49 / 0 / 1 / 0]$ & 0.123 \\
$0-24$ & $9[41 / 4 / 3 / 2]$ & $8[42 / 2 / 3 / 3]$ & 0.418 \\
$24-48$ & $1[49 / 1 / 0 / 0]$ & $1[49 / 1 / 0 / 0]$ & 0.5 \\
Vomiting incidence (h) & & & \\
$0-2$ & 7 & 1 & $0.027^{*}$ \\
$2-6$ & 1 & 0 & 0.315 \\
$6-24$ & 7 & 4 & 0.338 \\
$0-24$ & 15 & 5 & $0.012^{*}$ \\
$24-48$ & 0 & 0 & $0.024^{*}$ \\
Overall P0NV & $25(50)$ & $14(28)$ & \\
$0-48$ h $(\%)$ & & & 0.038 \\
Rescue antiemetic & 17 & $38 / 3 / 4 / 0 / 5$ & 0.070 \\
Patient satisfaction & $34 / 1 / 3 / 2 / 10$ & & \\
rating 1/2/3/4/5 & & & \\
\hline
\end{tabular}

Values are numbers or numbers (\%), $\mathrm{P}<0.05 *$ is statistically significant.

PONV: Post-operative nausea and vomiting

In our study, we found the overall incidence of PONV (0-48 h) to be significantly lower in palonosetron group (14/50 patients, $28 \%$ ) as compared to ondansetron group $(25 / 50$ patients, $50 \%, p=0.024)$ with fewer patients in palonosetron group requiring a rescue antiemetic $(p=0.038)$. Similarly, other authors have also found a lower incidence of PONV with palonosetron as compared to ondansetron. Park and Cho found a significantly lower incidence of PONV in $0-24 \mathrm{~h}$ with palonosetron as compared to ondansetron $(42.2 \%$ vs. $66.7 \%$, respectively) in patients undergoing gynecological laparoscopic surgery [12]. In patients, receiving fentanyl-based patient-controlled analgesia after thyroidectomy, incidence of PONV during the $24 \mathrm{~h}$ post-operative period was lower in the palonosetron group than in the ondansetron group ( $42 \%$ vs. $62 \%, p=0.045$ ) although investigators in this study had given ondansetron $8 \mathrm{mg}$ bolus and added $16 \mathrm{mg}$ to the IV PCA mixture, while palonosetron was given as a single bolus dose [7]. The incidence of PONV $(0-24 \mathrm{~h})$ following laparoscopic cholecystectomy was significantly lower in patients receiving palonosetron $(20 \%)$ as compared to ondansetron $(50 \%)$, but in this study, the investigators had used a lower dose of $4 \mathrm{mg}$ ondansetron as compared to $8 \mathrm{mg}$ in our study [17]. In patients undergoing bilateral laparoscopic tubal ligation as day care surgery, palonosetron $(0.075 \mathrm{mg})$ was found to be superior to ondansetron ( $8 \mathrm{mg}$ ) when administered as single pre-induction IV dose with an overall incidence of nausea and vomiting (0-72 h) to be significantly higher in the ondansetron group as compared to palonosetron group (20\% and $13.33 \%$ vs. $6.67 \%$ and $3.33 \%$, respectively) [18]. In variance with our results as well as those of other studies $[7,12,17,18]$, Laha et al. did not find the antiemetic efficacy of palonosetron $(0.075 \mathrm{mg})$ to be superior to ondansetron ( $4 \mathrm{mg}$ ) for preventing PONV during the first $24 \mathrm{~h}$ after laparoscopic cholecystectomy [16].

We found the incidence and severity of nausea to be comparable in both the groups at all the time intervals. Some investigators have reported a significantly lower incidence of nausea ( $24 \mathrm{~h}$ ) with palonosetron as compared to ondansetron ( $16 \%$ vs. $24 \%$ ) but may be this difference was due to a lower dose of ondansetron $4 \mathrm{mg}$ used in their study, as compared to $8 \mathrm{mg}$ used in ours [17]. Shadangi et al. found the overall incidence of nausea $(24 \mathrm{~h})$ to be much less with palonosetron as compared to ondansetron ( $16.7 \%$ vs. $43.4 \%, p=0.006)$ [19]. In their study, male-to-female ratio was 1 in ondansetron group and 1.3 in palonosetron group. The palonosetron group having more males than females could have influenced their result, female gender being a risk factor for PONV [19].
In our study, the incidence of vomiting was significantly less in Group P as compared to Group 0 in $0-2 \mathrm{~h}(2 \%$ vs. $14 \%, \mathrm{p}=0.027)$ and $0-24 \mathrm{~h}$ time intervals $(10 \%$ vs. $30 \%, p=0.012)$. However, it was comparable at all other time intervals, in the 48-h post-operative period, in the two groups. Bajwa et al., in their study, found the overall incidence of vomiting (0-72 h) to be $13.33 \%$ in ondansetron group and $3.33 \%$ in palonosetron group [18]. In their study, during the 6-12 h period, the incidence of vomiting was significantly less in palonosetron group as compared to ondansetron group [18]. In a meta-analysis, the efficacy of palonosetron was found to be better than ondansetron in preventing vomiting, at various time intervals, $0-2 \mathrm{~h}$ (RR, 0.45; 95\% CI, 0.26-0.78), 2-6 h (RR, 0.74; 95\% CI, 0.39-1.40), and 6-24 h (RR, 1.20; 95\% CI, 0.55-2.64) during the first 24 -h post-operatively after laparoscopic surgery [20].

A rescue antiemetic was required in greater number of patients in Group 0 (17/50 patients [34\%]) as compared to Group P (8/50 patients [16\%], $\mathrm{p}=0.038$ ), in our study. Other authors have also found the need of rescue antiemetics to be significantly higher in patients receiving ondansetron as compared to palonosetron [7,17]. The occurrence of side effects such as headache, dizziness, and constipation was comparable in both the study groups. Other authors have also found the safety profile of palonosetron and ondansetron to be comparable [19] Likewise, Liu et al., in a meta-analysis, to evaluate the efficacy and safety of palonosetron and ondansetron in preventing PONV in patients undergoing laparoscopic surgery found no significant differences in side effects between palonosetron and ondansetron [20].

Although we found palonosetron to be better than ondansetron in lowering the overall incidence of PONV in 0-48 h time interval, the patient satisfaction ratings in both the groups were comparable. Likewise, Park and Cho also found comparable patient satisfaction rates with the use of these two drugs for PONV prophylaxis [12].

Our study has several limitations. First, we did not have a control group, as we did not want to deprive patients' undergoing laparoscopic cholecystectomy of antiemetic prophylaxis, knowing the high incidence of PONV following this surgery. Second, we compared the efficacy of palonosetron and ondansetron on the basis of known optimal dosages, without knowledge of equipotent doses. Third, nausea and patient satisfaction score were subjective rating scales that may depend on the literacy levels of patients.

To conclude, palonosetron has better antiemetic efficacy than ondansetron in lowering the overall occurrence of PONV in $0-48 \mathrm{~h}$ time interval, in patients undergoing laparoscopic cholecystectomy with lesser number of patients requiring a rescue antiemetic. Its side effect profile and patient satisfaction rating are similar to ondansetron.

\section{AUTHORS' CONTRIBUTION}

Concept, design, intellectual content, and supervision - Dr. Ajay Kumar. Data collection, analysis, and interpretation - Dr. Ajay Kumar and Dr. Sumita Adhana. Data interpretation and literature review - Dr. Ajay Kumar, Dr. Sumita Adhana, and Dr. Puneet Dwivedi. Manuscript preparation and review - Dr. Ajay Kumar, Dr. Sumita Adhana, and Dr. Puneet Dwivedi.

\section{CONFLICTS OF INTEREST}

There are no conflicts of interest to declare.

\section{REFERENCES}

1. Daria U, Kumar V. Qualitative comparison of metoclopramide, ondansetron and granisetron alone and in combination with dexamethasone in the prevention of postoperative nausea and vomiting in day care laparoscopic gynaecological surgery under general anaesthesia. Asian J Pharm Clin Res 2012;5:165-7.

2. Apfel CC, Kranke P, Katz MH, Goepfert C, Papenfuss T, Rauch S, et al. Volatile anaesthetics may be the main cause of early but not delayed 
postoperative vomiting: A randomized controlled trial of factorial design. Br J Anaesth 2002;88:659-68.

3. Scuderi PE, Conlay LA. Postoperative nausea and vomiting and outcome. Int Anesthesiol Clin 2003;41:165-74.

4. Apfel CC, Laara E, Koivuranta M, Greim CA, Roewer N. A simplified risk score for predicting postoperative nausea and vomiting: Conclusions from cross-validations between two centers. Anesthesiology 1999;91:693-700.

5. Gan TJ. Risk factors for postoperative nausea and vomiting. Anesth Analg 2006;102:1884-98.

6. Gan TJ, Diemunsch P, Habib AS, Kovac A, Kranke P, Meyer TA, et al. Consensus guidelines for the management of postoperative nausea and vomiting. Anesth Analg 2014;118:85-113.

7. Moon YE, Joo J, Kim JE, Lee Y. Anti-emetic effect of ondansetron and palonosetron in thyroidectomy: A prospective, randomized, doubleblind study. Br J Anaesth 2012;108:417-22.

8. Patel SR, Patel LJ. Development and validation of first derivative spectroscopy method for simultaneous determination of ondansetron and metoclopramide in combined dosage form. Int J Pharm Pharm Sci 2011;3:85-8.

9. Yang LP, Scott LJ. Palonosetron: In the prevention of nausea and vomiting. Drugs 2009;69:2257-78.

10. Altannak NF. Comparative lc-ms stability indicatind assays of ondansetron hydrochloride/naloxone hydrochloride and metoclopramide hydrochloride/naloxone hydrochloride used in palliative care. Int J Pharm Pharm Sci 2015;7:109-13.

11. Grover VK, Mathew PJ, Hegde H. Efficacy of orally disintegrating ondansetron in preventing postoperative nausea and vomiting after laparoscopic cholecystectomy: A randomised, double-blind placebo controlled study. Anaesthesia 2009;64:595-600.

12. Park SK, Cho EJ. A randomized, double-blind trial of palonosetron compared with ondansetron in preventing postoperative nausea and vomiting after gynaecological laparoscopic surgery. J Int Med Res
2011;39:399-407.

13. Ghosh S, Pal A, Acharya A, Biswas C, Ghosh TR, Ghosh S. Palonosetron and palonosetron plus dexamethasone to prevent postoperative nausea and vomiting in patients undergoing laparoscopic cholecystectomy: A prospective, randomized, double-blind comparative study. Anesth Essays Res 2011;5:134-7.

14. Gan TJ, Meyer T, Apfel CC, Chung F, Davis PJ, Eubanks S, et al. Consensus guidelines for managing postoperative nausea and vomiting. Anesth Analg 2003;97:62-71.

15. Yuksek MS, Alici HA, Erdem AF, Cesur M. Comparison of prophylactic anti-emetic effects of ondansetron and dexamethasone in women undergoing day-case gynaecological laparoscopic surgery. J Int Med Res 2003;31:481-8.

16. Laha B, Hazra A, Mallick S. Evaluation of antiemetic effect of intravenous palonosetron versus intravenous ondansetron in laparoscopic cholecystectomy: A randomized controlled trial. Indian J Pharmacol 2013;45:24-9.

17. Bhalla J, Baduni N, Bansal P. Comparison of palonosetron with ondansetron for postoperative nausea and vomiting in patients undergoing laparoscopic cholecystectomy under general anesthesia. J Min Access Surg 2015;11:193-7.

18. Bajwa SS, Bajwa SK, Kaur J, Sharma V, Singh A, Singh A, et al. Palonosetron: A novel approach to control postoperative nausea and vomiting in day care surgery. Saudi J Anaesth 2011;5:19-24.

19. Shadangi BK, Agrawal J, Pandey R, Kumar A, Jain S, Mittal R, et al. A prospective, randomized, double-blind, comparative study of the efficacy of intravenous ondansetron and palonosetron for prevention of postoperative nausea and vomiting. Anaesth Pain Intensive Care 2013; $17: 55-8$

20. Liu Q, Zhou C, Bao Z, Zhu Y. Effects of palonosetron and ondansetron on preventing nausea and vomiting after laparoscopic surgery. J Int Med Res 2018;46:411-20. 